\title{
A 3-year Longitudinal Study of the Effects of Physical Activity and Sedentary Behaviors on Childhood Obesity in China: The Childhood Obesity Study in China Mega-Cities
}

\section{Xiaomin Sun}

Global Health Institute, School of Public Health, Xi'an Jiaotong University Health Science Center

\section{Bingtong Zhao}

Global Health Institute, School of Public Health, Xi'an Jiaotong University Health Science Center Jin Liu

Department of Health Behavior and Policy, School of Medicine, Virginia Commonwealth University

\section{Yun Wang}

National Institute for Nutrition and Health, Chinese center for disease control and prevention

Fei Xu

Nanjing Municipal Center for Disease Control \& Prevention

Youfa Wang ( $\square$ youfawang@gmail.com )

Global Health Institute

\section{Hong Xue}

Department of Health Behavior and Policy, School of Medicine, Virginia Commonwealth Univerity

\section{Research}

Keywords: physical activity, sedentary behavior, overweight, obesity, China, child

Posted Date: June 2nd, 2020

DOl: https://doi.org/10.21203/rs.3.rs-32131/v1

License: (c) (1) This work is licensed under a Creative Commons Attribution 4.0 International License. Read Full License 


\section{Abstract}

Objectives: Examine school children's physical activity (PA) and sedentary behaviors (SB) during 20152017 and study their effects on children's weight status and their relevant gender differences in China.

Methods: This open cohort study included students from 5 major cities (Beijing, Shanghai, Xi'an, Nanjing, and Chengdu) across China. Data were collected from students in 2015, 2016, and $2017(n=5,535)$ and from their parents and school personnel. Children's weight, height, and waist circumference were measured. SB and PA factors were evaluated using questionnaires. Mixed effects models examined the relationship between weight status and PA/SB-associated factors using this longitudinal data.

Results: These children had high rates of obesity (12.4\%, 95\% Cl 11.6\%-13.3\%) and central obesity (28.1\%, 95\% Cl 26.9\%-29.3\%) during 2015-2017. Boys were more likely to be obese (16.5\% vs. $8.4 \%)$ and central obese $(36.3 \%$ vs. $19.8 \%)$ and spent more time in screen viewing than girls (hours/week \pm SD: $2015,1.8 \pm$ 2.5 vs. $1.5 \pm 2.0 ; 2016,2.0 \pm 2.4$ vs. $1.8 \pm 2.5 ; 2017,1.7 \pm 2.3$ vs. $1.4 \pm 2.1$ hours/week). Those who walked $\triangle 5$ minutes on their average daily walk to school were more likely to be obese (OR: $1.96,95 \% \mathrm{Cl} 1.03$ 3.73) than those who spent $\geq 15$ minutes on walking to school. When stratified by gender, this higher risk was only observed in girls (OR: $3.01,95 \% \mathrm{Cl} 1.09-8.35$ ). Children who spent more time in screen viewing were more likely to be obese (OR: 1.13, 95\% Cl 1.06-1.21) and have central obesity (OR: 1.05, 95\% Cl 1.021.09). The association for obesity was consistent in boys and girls (boys, OR: 1.15, 95\% Cl 1.05-1.25; girls, OR: $1.12,95 \% \mathrm{Cl} 1.00-1.24)$.

Conclusions: More screen time and less active time were risk factors for developing obesity in urban Chinese children. The associations varied by gender.

\section{Introduction}

With the rapid development of the social economy and changes in the lifestyle of residents, the prevalence of overweight and obesity (ov/ob) has increased rapidly in China in the past three decades, especially in the mega-cities (like Beijing and Shanghai) [1-4]. National data show that ov/ob prevalence among school children in China has increased from less than 3\% in 1985 to $5.3 \%$ in 1995 and approximately $20.5 \%$ in 2014 , with boys being about twice as likely to be ov/ob as girls $[5,6]$. These increases are cause for concern, since children who are obese have a higher risk of developing many health problems, including type 2 diabetes, high blood pressure, and sleep disorders [7-9].

Childhood physical activity (PA) and sedentary behaviors (SB) are important risk factors for obesity [10]. Studies have documented shifts in PA over the past couple of decades among Chinese adults, revealing decreases in PA and increases in SB [11], but similar analyses have not been done among Chinese children and adolescents. Previous studies conducted in western countries have indicated that less time spent in PA and higher frequencies of SB was associated with unfavorable body composition in children and adolescents [12-15]. However, limited studies have evaluated the association of changes of PA and 
SB with the prevalence of obesity in children and adolescents [15], especially in countries with a Confucian heritage culture such as China, Japan, Korea, and Singapore [16, 17].

Given that parents are the primary caregivers for children, parents' support has been linked to higher levels of PA among children and adolescents $[18,19]$, though Fogelholm and colleagues found the effect of parental involvement in PA may have gender differences [20]. Some difference was also observed in limited PA at school and in increased SB [21-24]. In general, boys are more active than girls, especially among adolescents, while SB increases in both genders with age and is higher in girls [24, 25]. However, there is no in-depth research based on longitudinal data on the gender-specific trends in PA and SB and their associations with obesity and central obesity in Chinese children and adolescents.

To fill these gaps, using longitudinal data collected from students and their parents in five mega-cities across China, this study investigated: 1) trends in children's overweight/obesity, central obesity rates, and related $\mathrm{PA}$ and $\mathrm{SB}$; and 2) associations between $\mathrm{PA}$ and $\mathrm{SB}$ changes and their weight status, and tested related gender differences. These findings provide useful insights for fighting the childhood obesity epidemic.

\section{Methods And Materials}

\section{Study Design And Study Sample}

The Childhood Obesity Study in China Mega-cities (COCM) was a US NIH-funded longitudinal study aimed at examining the etiology of childhood obesity and chronic diseases in China, especially in major cities, which have been experiencing rapid socioeconomic changes over the past three decades. These transitions have resulted in many dramatic changes in social environments and people's lifestyles, which have led to an increase in obesity and other health problems. Initially, four major cities were included in the 2015 (baseline) survey for the study, including Beijing (China's capital, in North China), Shanghai (the largest and most economically developed city in China, in Southeast China), Nanjing (China's old capital before 1949, the capital of Jiangsu province, in Southeast China), and Xi'an (the capital of Shaanxi province, in Northwest China, which has served as the capital of China for 13 dynasties and over 1,300 years). Chengdu (in Southwest China, the capital of Sichuan province, one of the national central cities) was added in 2016. In each city, two primary schools and two middle schools were included. In each school, a class from each grade (grades 3-6 in primary schools, and grades 7-9 in middle schools) was included. Written informed consent was obtained from parents or children.

Children with missing data on age, gender, weight, height, and PA- and SB-related measurements were excluded from analysis $(n=171)$. For cross-sectional data analysis, sample characteristics of 5,535 participants were described across the three waves; for PA- and SB-related factors, the children's first available observation during 2015-2017 (3,268 different children) were presented by gender. For longitudinal analysis of the associations, we included 2,762 students with the needed data from all three waves from 2015 to 2017. 


\section{Assessment and measures}

1) Anthropometric measures

Height was measured by a Seca 213 Portable Stadiometer Height-Rod with a resolution of 0.1 centimeter; body weight was measured by a Seca 877 electronic flat scale with a resolution of 0.1 kilogram. Waist circumference (WC) was measured by a tape with a resolution of 0.1 centimeter.

Children's BMI (body mass index, $\mathrm{kg} / \mathrm{m}^{2}$ ) was calculated as body weight divided by height squared $\left(\mathrm{kg} / \mathrm{m}^{2}\right)$. Overweight and obesity were defined based on age-gender-specific BMI curves developed by the Working Group on Obesity in China (WGOC) that correspond to BMI levels of 24 and 28 at age 18 [26], respectively. Abdominal obesity was defined as $\mathrm{WHtR} \geq 0.46$ [27].

2) Physical activity (PA) and sedentary behaviors (SB)

PA factors: PA time in school education classes (minutes/week), school physical examination (yes/no), extracurricular PA requirement (yes/no), access to sporting equipment at school ("unavailable", "not enough", "sometimes enough" and "fair enough"), and the walking time on the way to school (" $<5 \mathrm{~min}$ ", " 5 $\sim 15 \mathrm{~min}$ " and "> $15 \mathrm{~min}$ ").

Considering the influence of parental support on the associations between PA, SB, and children's weight status, the following measurements were included: mothers' paired PA (yes/no), fathers' paired PA (yes/no).

The SB outcome measures included: (1) screen viewing (hours/week) and (2) homework (minutes/day). Activities in the screen viewing category included watching TV, video games, videotapes, VCDs, DVDs, and movies/videos online, but did not include computer time (e.g., surfing the Internet) for homework purposes per week. Children reported on homework time in a separate question.

3) Parental and household characteristics

To consider the influence of family and household characteristics on the associations among PA, SB, and children's weight status, self-reported height and weight of mothers and fathers were used to calculate parental BMI, and overweight and obesity were defined based on the standards set by the Working Group on Obesity in China (WGOC) (BMI $\geq 24 \mathrm{~kg} / \mathrm{m}^{2}$ ) [22]. Highest maternal education ("middle school or lower", "high and vocational schools", and "college or above"), and family home ownership (rent or share residency with relatives, "own an apartment", and "own a house") were collected using questionnaires.

\section{4) Covariates}

Covariates included age (in years), parental BMI (in $\mathrm{kg} / \mathrm{m}^{2}$ ), maternal highest education ("middle school or lower", "high and vocational schools", and "college or above"), family home ownership ("rent or share 
residency with relatives", "own an apartment", and "own a house"), and family living environment ("very safe", "safe", and "unsafe").

\section{Statistical Analysis}

For participants' characteristics over the survey years, continuous variables were reported as means (standard deviation, SDs) and compared with the Mann-Whitney-Wilcoxon test. Categorical variables were reported as percentages, and the differences were compared with the chi-square test.

Then mixed-effects models were fitted to investigate the associations between ov/ob (also central obesity) and PA/SB-related measures while adjusting for other covariates. The models adjusted for age, parental BMIs, maternal highest education level, living environment, the city, and the year. Analysis stratified by gender was conducted to test gender-based differences in the associations.

All statistical analyses were conducted using Stata 15.0 (Stata Corp, College Station, Texas, USA). The effected size was reported as odds ratios (ORs) and 95\% confidence interval $(95 \% \mathrm{Cl})$.

\section{Results}

\section{Participants' characteristics and prevalence of overweight and obesity during 2015-2017}

Table 1 reports the study participants' characteristics. Their average BMls $(19.2 \pm 3.9$ vs. $19.3 \pm 3.7$ vs $19.4 \pm 3.7 \mathrm{~kg} / \mathrm{m}^{2}$ ) and prevalence of obesity (13.2\% vs. $12.0 \%$ vs. $\left.12.2 \%\right)$ were similar during $2015-2017$, but the prevalence of central obesity increased from $27.3 \%$ in 2015 to $30.9 \%$ in 2017 . More boys than girls were found to have obesity or central obesity in 2015 (obesity $17.1 \%$ vs $9.2 \%$, respectively; central obesity, $35.3 \%$ vs $19.1 \%$, respectively), 2016 (obesity $15.8 \%$ vs $8.1 \%$, respectively; central obesity, $34.2 \%$ vs $17.3 \%$, respectively), and 2017 (obesity $16.5 \%$ vs $7.9 \%$, respectively; central obesity, $39.2 \%$ vs $22.7 \%$, respectively). 
Table 1

Sample characteristics of Chinese children in the 5 large cities across China during 2015-2017: The Childhood Obesity Study in China Mega-cities*

\section{Characteristics}

\begin{abstract}
$2015(n=$ 1624)
\end{abstract}

2016 ( $n=$ 1938) $2017(n=$
$P^{\#}$

A. Child obesity related measures

BMI, mean(SD)

19.2

(3.9) $\quad 19.3$

(3.7) $\quad 19.4$

(3.7)

0.012

Waist circumference, mean(SD)

$66.0 \quad(10.3) \quad 65.6$

$(10.2)$

67.3

(10.1)

$\hat{0.001}$

WHtR, mean(SD)

0.44

$(0.06)$

0.43

$(0.06)$

$0.44 \quad(0.06)$

0.001

Overweight and obesity ${ }^{\mathrm{a}}, \mathrm{n}(\%)$

$\begin{array}{lllllll}470 & (28.9) & 548 & (28.3) & 570 & (28.9) & 0.996\end{array}$

Obesity $^{\mathrm{a}}, \mathrm{n}(\%)$

215

(13.2)

449

(27.3) 510

(12.0)

241

(12.2) $\quad 0.358$

Central obesity ${ }^{\mathrm{b}}, \mathrm{n}(\%)$

B. Child characteristics

Age (in years), mean(SD)

11.0

$(2.0)$

11.3

(2.0)

11.3

(2.0)

$<$

0.001

Father's BMI, mean(SD)

24.3

(3.3)

24.4

(4.1) $\quad 24.2$

(3.7)

0.015

Overweight and obese father, $n(\%)$

899

(55.4) 992

(51.2) $\quad 1003$

(50.8)

0.007

Mother's BMI, mean(SD)

22.2

(3.4)

22.3

(3.9)

22.2

(3.7)

0.078

Overweight and obese mother, n(\%)

$428 \quad(26.4) \quad 496$

(25.6)

511

(25.9)

0.757

C. Family characteristics

0.001

Mother's highest education levels,

$\mathrm{n}(\%)$

Middle school or below

$\begin{array}{llllll}401 & (25.6) & 436 & (23.3) & 392 & (20.8) \\ 451 & (28.8) & 523 & (28.0) & 528 & (28.0) \\ 714 & (45.6) & 909 & (48.7) & 966 & (51.2)\end{array}$

College or above

714

Family living environment, $n(\%)$

Very safe

341

(21.7)

480

(25.9)

589

(31.6)

Safe

1076

(68.2)

159

(10.1)

157

(8.5)

(65.6) $1165 \quad$ (62.5)

Unsafe

159 


\begin{tabular}{|c|c|c|c|c|}
\hline Characteristics & $\begin{array}{l}2015(n= \\
1624)\end{array}$ & $\begin{array}{l}2016 \\
1938)\end{array}(n=$ & $\begin{array}{l}2017(n= \\
1973)\end{array}(n=$ & $P^{\#}$ \\
\hline \multicolumn{5}{|c|}{$\begin{array}{l}\text { The five cities included in The Childhood Obesity Study in China Mega-cities are Beijing, Shanghai, } \\
\text { Xi'an, Nanjing, and Chengdu across China. Abbreviation: BMl, body mass index; WHtR, waist-height } \\
\text { ratio. *the whole sample size for each wave; }{ }^{\text {a }} \text { overweight/obesity were defined based on the working } \\
\text { group on obesity in China -recommended age-and sex-specific cutoffs corresponding to BMI } \geq 24 \text { and } \\
28 \mathrm{~kg} \mathrm{~m}^{-2} \text { at age } 18 \text { years, respectively; }{ }^{b} \text { central obesity was defined based on the criterial for Chinese } \\
\text { children (WHtR } \geq 0.46 \text { ). }{ }^{\#} \mathrm{P} \text { were calculated by using chi-square test for categorical variables or Mann- } \\
\text { Whitney-Wilcoxon test for continuous variables between } 2015 \text { and } 2017 \text {. }\end{array}$} \\
\hline
\end{tabular}

\section{Associations between changes of PA and SB related factors and weight status in longitudinal data analysis}

Mixed-effects models were used to assess the longitudinal associations between obesity and PA/SB factors (Table 3 and Supplemental Table 1). Compared with children who spent more than 15 minutes walking time on the way to school, children who walked less than 5 minutes had a higher obesity risk (OR: $1.96,95 \% \mathrm{Cl} 1.03-3.73)$. When stratified by gender, the higher risk was only observed in girls (OR: 3.01 , $95 \% \mathrm{Cl} 1.09-8.35)$. Children who spent more time in screen viewing had a higher risk to develop obesity (OR: $1.13,95 \% \mathrm{Cl} 1.06-1.21$ ) and central obesity (OR: 1.05, 95\% $\mathrm{Cl} 1.02-1.09$ ). When stratified by gender, the associations with obesity were consistent in boys and girls (boys, OR: 1.15, 95\% Cl 1.05-1.25; girls, OR: $1.12,95 \% \mathrm{Cl} 1.00-1.24)$, while the association with central obesity was only observed in boys (1.06, 95\% Cl 1.02-1.10). 
Table 3

Longitudinal data analysis using mixed effect models studying effects of PA and SB related factors on obesity (OR $(95 \% \mathrm{Cl}))$ : The Childhood Obesity Study in China Mega-cities*

\section{Table 2. Physical activity of school children in 5-mega cities in China 2015-2017 : The Childhood} Obesity Study in China Mega-cities

$\begin{array}{llll}\text { Characteristics } & 2015 & 2016^{\mathrm{a}} & 2017^{\mathrm{b}} \\ \text { A. Boys and girls } & \mathrm{N}=1624 & \mathrm{~N}=878 & \mathrm{~N}=766\end{array}$

Walking time on the way to

school (minutes/day), $\mathrm{n}(\%)$

$<5$

557

$(34.5)$

361

(41.3) $\quad 343$

(44.3)

5-15

892

(55.3)

430

(49.2) $\quad 359$

(47.4)

$>15$

165

(10.2)

83

(9.5)

55

Father-child paired physical

activity (yes), $n(\%)$

$1463 \quad(90.1)$

787

(89.8) 606

(79.1)

$<$

Mother-child paired

1468

physical activity (yes), n(\%)

Physical activity in school $\quad 138.4 \quad$ (31.9)

education classes

(minutes/week)

School physical

examination (yes), $\mathrm{n}(\%)$

Extracurricular physical

activity requirement (yes),

$\mathrm{n}(\%)$

Access to sporting

equipment at school, $\mathrm{n}(\%)$

Unavailable

Not enough

Sometimes enough

Fair enough

B. Boys

Walking time on the way to

school (minutes/day), n(\%)

\begin{tabular}{lllllll}
$<5$ & 297 & $(36.2)$ & 177 & $(40.3)$ & 173 & $(45.5)$ \\
\hline $5-15$ & 437 & $(53.2)$ & 224 & $(51.0)$ & 181 & $(47.6)$ \\
$>15$ & 87 & $(10.6)$ & 38 & $(8.7)$ & 26 & $(6.8)$
\end{tabular}


Table 2. Physical activity of school children in 5-mega cities in China 2015-2017 : The Childhood Obesity Study in China Mega-cities

\begin{tabular}{|c|c|c|c|c|c|c|c|}
\hline $\begin{array}{l}\text { Father-child paired physical } \\
\text { activity (yes), } n(\%)\end{array}$ & 735 & $(88.7)$ & 391 & $(88.5)$ & 306 & $(79.5)$ & ¿.001 \\
\hline $\begin{array}{l}\text { Mother-child paired } \\
\text { physical activity (yes), n(\%) }\end{array}$ & 755 & $(91.1)$ & 390 & $(88.2)$ & 293 & $(76.1)$ & $\dot{0} 001$ \\
\hline $\begin{array}{l}\text { Physical activity in school } \\
\text { education classes } \\
\text { (minutes/week) }\end{array}$ & 137.6 & $(31.5)$ & 115.2 & $(37.4)$ & 139.7 & $(29.9)$ & 0.528 \\
\hline $\begin{array}{l}\text { School physical } \\
\text { examination (yes), } n(\%)\end{array}$ & 829 & $(100.0)$ & 393 & $(100.0)$ & 407 & $(100.0)$ & \\
\hline $\begin{array}{l}\text { Extracurricular physical } \\
\text { activity requirement (yes), } \\
\mathrm{n}(\%)\end{array}$ & 768 & $(92.6)$ & 393 & $(88.7)$ & 363 & $(94.3)$ & 0.291 \\
\hline $\begin{array}{l}\text { Access to sporting } \\
\text { equipment at school, } n(\%)\end{array}$ & & & & & & & 0.008 \\
\hline Unavailable & 96 & $(12.2)$ & 34 & $(8.5)$ & 67 & $(18.7)$ & \\
\hline Not enough & 65 & $(8.2)$ & 52 & $(13.0)$ & 36 & $(10.0)$ & \\
\hline Sometimes enough & 148 & $(18.8)$ & 70 & $(17.5)$ & 70 & $(19.5)$ & \\
\hline Fair enough & 480 & $(60.8)$ & 243 & $(60.9)$ & 186 & $(51.80)$ & \\
\hline C. Girls & $N=795$ & & $N=435$ & & $N=381$ & & \\
\hline $\begin{array}{l}\text { Walking time on the way to } \\
\text { school (minutes/day), n(\%) }\end{array}$ & & & & & & & $\dot{\delta} 001$ \\
\hline$<5$ & 260 & $(33.0)$ & 184 & $(42.3)$ & 170 & $(45.1)$ & \\
\hline $5-15$ & 455 & $(57.4)$ & 206 & $(47.4)$ & 178 & $(47.2)$ & \\
\hline$>15$ & 78 & $(9.8)$ & 45 & $(10.3)$ & 29 & (7.7) & \\
\hline $\begin{array}{l}\text { Father-child paired physical } \\
\text { activity (yes), } n(\%)\end{array}$ & 728 & (91.6) & 396 & $(91.0)$ & 300 & (78.7) & $\hat{0} 001$ \\
\hline $\begin{array}{l}\text { Mother-child paired } \\
\text { physical activity (yes), n(\%) }\end{array}$ & 713 & $(89.7)$ & 390 & $(90.0)$ & 262 & $(68.8)$ & $\dot{0} 001$ \\
\hline $\begin{array}{l}\text { Physical activity in school } \\
\text { education classes } \\
\text { (minutes/week) }\end{array}$ & 139.2 & $(32.2)$ & 113.5 & $(39.1)$ & 139.7 & $(29.4)$ & 0.954 \\
\hline $\begin{array}{l}\text { School physical } \\
\text { examination (yes), } n(\%)\end{array}$ & 795 & $(100.0)$ & 387 & $(100.0)$ & 381 & $(100.0)$ & \\
\hline $\begin{array}{l}\text { Extracurricular physical } \\
\text { activity requirement (yes), } \\
\mathrm{n}(\%)\end{array}$ & 722 & (90.8) & 387 & (89.0) & 359 & (94.2) & 0.045 \\
\hline
\end{tabular}


Table 2. Physical activity of school children in 5-mega cities in China 2015-2017 : The Childhood Obesity Study in China Mega-cities

Access to sporting equipment at school, $\mathrm{n}(\%)$

\begin{tabular}{lllllll} 
Unavailable & 82 & $(10.6)$ & 45 & $(11.6)$ & 56 & $(15.4)$ \\
\hline Not enough & 52 & $(6.7)$ & 44 & $(11.3)$ & 33 & $(9.1)$ \\
\hline Sometimes enough & 162 & $(21.0)$ & 80 & $(20.6)$ & 70 & $(19.3)$ \\
\hline Fair enough & 475 & $(61.6)$ & 219 & $(56.4)$ & 204 & $(56.2)$
\end{tabular}

a, Students who participated in the survey in 2016 for the first time; b. Students who participated in the survey in 2017 for the first time. \#P were calculated by using chi-square test for categorical variables or Mann-Whitney-Wilcoxon test for continuous variables between 2015 and 2017.

$\begin{array}{lll}\text { Overall Boys } & \text { Girls }\end{array}$

\begin{tabular}{|c|c|c|c|c|c|c|}
\hline Independent variable & \multicolumn{2}{|c|}{ OR ( $95 \% \mathrm{Cl})$} & \multicolumn{2}{|c|}{ OR ( $95 \% \mathrm{Cl})$} & \multicolumn{2}{|c|}{ OR ( $95 \% \mathrm{Cl})$} \\
\hline \multicolumn{7}{|l|}{$\begin{array}{l}\text { Walking time on way to } \\
\text { school (minutes/day) }\end{array}$} \\
\hline$<5$ & 1.959 & $\begin{array}{l}(1.030, \\
3.726)\end{array}$ & 1.414 & $\begin{array}{l}(0.586, \\
3.411)\end{array}$ & 3.009 & $\begin{array}{l}(1.085, \\
8.346)\end{array}$ \\
\hline $5-15$ & 1.724 & $\begin{array}{l}(0.929, \\
3.197)\end{array}$ & 1.226 & $\begin{array}{l}(0.523, \\
2.875)\end{array}$ & 2.616 & $\begin{array}{l}(0.990, \\
6.908)\end{array}$ \\
\hline
\end{tabular}

$>15$ (ref)

Access to sporting

equipment at school

$\begin{array}{lcccccc}\text { Unavailable } & 0.949 & \begin{array}{c}(0.571, \\ 1.576)\end{array} & 0.708 & \begin{array}{l}(0.348, \\ 1.438)\end{array} & 1.390 & \begin{array}{l}(0.646, \\ 2.992)\end{array} \\ \text { Not enough } & 1.027 & \begin{array}{l}(0.609, \\ 1.732)\end{array} & 1.097 & \begin{array}{l}(0.539, \\ 2.233)\end{array} & 0.950 & (0.415, \\ \text { Sometimes enough } & 1.165 & \begin{array}{l}(0.781, \\ 1.738)\end{array} & 0.939 & \begin{array}{l}(0.526, \\ 1.676)\end{array} & 1.445 & (0.805, \\ & & & 1.675)\end{array}$

Fair enough (ref)

\begin{tabular}{lcccccc}
$\begin{array}{l}\text { Homework time } \\
\text { (minutes/day) }\end{array}$ & 1.000 & $\begin{array}{l}(0.998, \\
1.003)\end{array}$ & 0.999 & $\begin{array}{l}(0.997, \\
1.003)\end{array}$ & 1.001 & $\begin{array}{l}(0.998, \\
1.004)\end{array}$ \\
\hline $\begin{array}{l}\text { Screening time } \\
\text { (minutes/week) }\end{array}$ & 1.131 & $\begin{array}{l}(1.059, \\
1.207)\end{array}$ & 1.147 & $\begin{array}{l}(1.052, \\
1.251)\end{array}$ & 1.116 & $(1.001$, \\
$\begin{array}{l}\text { Physical activity in school } \\
\text { education classes } \\
\text { (minutes/week) }\end{array}$ & 1.003 & $\begin{array}{l}(0.998, \\
1.009)\end{array}$ & 0.999 & $\begin{array}{l}(0.992, \\
1.008)\end{array}$ & 1.008 & $\begin{array}{l}(0.999, \\
1.016)\end{array}$
\end{tabular}


Table 2. Physical activity of school children in 5-mega cities in China 2015-2017 : The Childhood Obesity Study in China Mega-cities

${ }^{*}, 2762$ students with needed repeated data from all three waves from 2015 to 2017 were included. The mixed models adjusted for age, sex, walking time on the way to school, time of homework, screening time, mother/father paired physical activity, mother's highest education levels, family living environment, parental BMI, PA in school, access to sporting equipment, city, and year.

\section{Supplemental Table 1 Longitudinal data analysis using mixed effect models studying effects of PA and SB related factors on central obesity $(\mathrm{OR}(95 \% \mathrm{Cl}))$ : The Childhood Obesity Study in China Mega-cities *}

\begin{tabular}{|c|c|c|c|c|c|c|}
\hline & \multicolumn{2}{|c|}{ Overall } & \multicolumn{2}{|l|}{ Boys } & \multicolumn{2}{|l|}{ Girls } \\
\hline Independent variable & \multicolumn{2}{|c|}{ OR ( $95 \% \mathrm{Cl})$} & \multicolumn{2}{|c|}{ OR ( $95 \% \mathrm{Cl})$} & \multicolumn{2}{|c|}{ OR ( $95 \% \mathrm{Cl})$} \\
\hline \multicolumn{7}{|c|}{$\begin{array}{l}\text { Walking time on the way to } \\
\text { school (minutes/day) }\end{array}$} \\
\hline$<5$ & 0.821 & $\begin{array}{l}(0.344, \\
1.957)\end{array}$ & 1.181 & $\begin{array}{l}(0.414, \\
3.370)\end{array}$ & 0.328 & $\begin{array}{l}(0.073, \\
1.479)\end{array}$ \\
\hline $5-15$ & 0.782 & $\begin{array}{l}(0.328, \\
1.862)\end{array}$ & 1.098 & $\begin{array}{l}(0.385 \\
3.131)\end{array}$ & 0.318 & $\begin{array}{l}(0.071 \\
1.431)^{\prime}\end{array}$ \\
\hline \multicolumn{7}{|l|}{$>15$ (ref) } \\
\hline \multicolumn{7}{|l|}{$\begin{array}{l}\text { Access to sporting } \\
\text { equipment at school }\end{array}$} \\
\hline Unavailable & 0.870 & $\begin{array}{l}(0.688, \\
1.101)\end{array}$ & 0.767 & $\begin{array}{l}(0.561, \\
1.047)\end{array}$ & 1.073 & $\begin{array}{l}(0.748, \\
1.539)\end{array}$ \\
\hline Not enough & 0.886 & $\begin{array}{l}(0.693, \\
1.133)\end{array}$ & 0.925 & $\begin{array}{l}(0.673 \\
1.270)\end{array}$ & 0.825 & $\begin{array}{l}(0.549, \\
1.239)\end{array}$ \\
\hline Sometimes enough & 0.993 & $\begin{array}{l}(0.823, \\
1.198)\end{array}$ & 0.913 & $\begin{array}{l}(0.708, \\
1.177)\end{array}$ & 1.096 & $\begin{array}{l}(0.825, \\
1.456)\end{array}$ \\
\hline
\end{tabular}

Fair enough (ref)

$\begin{array}{lllllll}\begin{array}{l}\text { Homework time } \\ \text { (minutes/day) }\end{array} & 1.000 & \begin{array}{l}(0.999, \\ 1.001)\end{array} & 1.000 & \begin{array}{l}(0.999, \\ 1.001)\end{array} & 1.001 & \begin{array}{l}(0.999, \\ 1.002)\end{array} \\ \begin{array}{l}\text { Screening time } \\ \text { (minutes/week) }\end{array} & 1.053 & \begin{array}{l}(1.022, \\ 1.085)\end{array} & 1.061 & \begin{array}{l}(1.021, \\ 1.103)\end{array} & 1.045 & \begin{array}{l}(0.993, \\ 1.100)\end{array} \\ \begin{array}{l}\text { Physical activity in school } \\ \text { education classes }\end{array} & 1.002 & (1.000,1.005) & 1.000 & \begin{array}{l}(0.997, \\ 1.004)\end{array} & 1.006 & \begin{array}{l}(1.001, \\ \text { (m.010) }\end{array}\end{array}$

(minutes/week)

*, 2762 students with needed repeated data from all three waves from 2015 to 2017 were included. The mixed models were adjusted with age, sex, walking time on the way to school, time of homework, screening time, mother/father paired physical activity, mother's highest education levels, family living environment, parental BMI, PA in school, access to sporting equipment, city, and year. 


\section{Discussion}

This study explored the influence of PA and SB measures on children's weight status changes using longitudinal data collected during 2015-2017 from five mega-cities across China. About 1/3 of children in big cities in China had central obesity, with more boys being obese than girls. A slight decrease was observed from 2015 and 2017 in screen viewing time, but not in homework time. Children who spent more screen time were more likely to be obese and have central obesity, but similar associations were not observed in homework time. The stratified analysis found that, when spending more time in screen viewing, boys were more likely to have a higher risk of both obesity and central obesity, while girls may have only a higher obesity risk. In addition, children who spent less walking time on the way to school were more likely to be obese, though the association was only observed in girls, but not in boys.

Some systematic reviews have concluded that lower levels of SB were associated with lower levels of body fatness, while the association was less consistent in longitudinal studies in children and adolescents [28]. For example, one study conducted in the UK [14] did not observe any associations between SB and adiposity in a prospective cohort study conducted in children. Another study [29] found increases in SB were associated with higher increases only in BMI above the 50th percentile. Compared with western countries, students in Confucian heritage cultures in some Asian countries like China, South Korea, and Singapore were reported to have longer homework time and less screen time [30-32]. Although evidence from cross-sectional studies have suggested positive associations of both homework and screen time with obesity risk [33-36], previously the longitudinal relationships were not evaluated in Chinese children and adolescents.

Previous studies, predominantly those conducted in industrialized countries like the United States, have been limited by their inability to distinguish between SB time spent screen viewing and SB time spent on homework; our data was configured to capture this information. Prior evidence has shown that watching television rather than overall SB time is more likely to affect adiposity, which may be due to unhealthy eating messages emanating from TV as well as possible over-consumption during watching TV [37]. Consistently, our study indicated that screen viewing time, but not homework time, was positively associated with obesity and central obesity risks.

A large national survey including 131,859 children and adolescents in China reported that compared with girls, boys spent more time on screen viewing and were less likely to meet the guideline of limiting screen viewing time [38]. The result was consistent with ours. When stratified by gender, we observed that boys had more screen time and were more likely to have a higher risk of central obesity. Ren and colleagues [39], on the other hand, found homework and screen viewing were positively related to BMI z-score in girls, but not in boys.

Creating active school communities including walking or biking is a useful way to increase school children's PA levels and to prevent obesity [40]. Research suggests that in recent years bicycle usage in Chinese mega-cities has been declining (Beijing, 14\%; Shanghai, 10\%), although three decades ago the 
rate was very high [41]. This is reflected in the habits of children as well as adults. In the present study, while $36.8 \%$ of children walked to school, only $8.4 \%$ of children chose to ride a bicycle go to school.

Recently, a systematic review that evaluated the associations between adiposity and active communities reported mixed results. A limitation of the 38 studies reviewed is that only 5 measured waist circumference, and very few of them conducted longitudinal data analysis [42]. Our study has the advantage of doing both. Another study found that the inverse associations between BMI z-score and active commuting were greatly mediated by moderate to vigorous physical activity levels [43]. In our study, we observed that children who spent less time on walking to school were significantly more at risk for obesity, but not for central obesity, which was also consistent with the evidence from some crosssectional studies $[43,44]$. Still other studies that focused on screen time had also suggested that compared with PA, children's screen viewing time was more closely associated with overweight and central obesity $[45,46]$, an association our study corroborates. These evidences may partly explain the difference in the relationship between obesity and screen viewing time vs. that with walking time.

The school built environment was reported to be closely related to PA, but its associations with ov/ob were inconsistent [47-49]. Rashad and colleagues identified a significant and negative association between access to the sports field at school and BMI [50], while another study reported that BMI was not associated with PA equipment, or vise versa [51, 52]. On the other hand, early-life living conditions are important for obesity development. However, neither parent- paired PA nor family living environment was associated with obesity or central obesity prevalence in the present study. Consistently Zhang et al. [53] have reported that the percentage of parents' encouragement of exercise in non-obese children was higher than for obese children, but the study failed to observe a significant relationship between obesity and parents' encouragement of exercise. Although some studies have reported that living in substandard housing and parental attitude were associated with elevated BMI, a recent systematic review summarized that the relevance of home environment to child weight extended beyond a single indicator [54].

The main strengths of our study include the longitudinal data analysis and stratified analysis to examine time trends in PA and SB and its associations with general and central obesity in Chinese children. The study has two major limitations. First, it only studied children in large cities in China, but not nationwide. Second, the follow-up period of 3 years is not long.

In conclusion, the prevalence of obesity is high, and much higher in boys than in girls, in big cities across China. Children who had more sedentary behaviors or/and less active time were more likely to become obese, especially girls. Gender differences in behaviors and associated risks should be considered in childhood obesity interventions. Intervention programs aiming to reduce screen viewing time and increase active commuting time are needed for obesity prevention in China.

\section{Declarations}

\section{Availability of data and materials}


The datasets generated and/or analyzed during the current study are not available due to ethics board requirements, but are available from the corresponding author on reasonable request.

\section{Ethics approval and consent to participate}

The study was approved by the Ethical Committee of The State University of New York at Buffalo (FWA00008824) and related collaboration institutes in China. Consent from parents and school administrators and assent from children were obtained before investigation.

\section{Consent for publication}

Not applicable

\section{Competing interests}

The authors declare that they have no competing interests.

\section{Funding}

This study was funded in part by the National Institute of Health (NIH, U54 HD070725). The U54 project (U54 HD070725) is funded by the Eunice Kennedy Shriver National Institute of Child Health and Human Development (NICHD) and the Office of the Director, National Institutes of Health (OD). The content of the paper is solely the responsibility of the authors and does not necessarily represent the official views of the funders. The National Institute of Health had no role in the design, analysis or writing of this article.

\section{Author's contributions}

YW, HX and XS designed the analysis, BZ and JL analyzed the data and XS and BZ wrote the draft of the manuscript. YW, HX, FX, and LW provided a critical review of the initial and subsequent versions of the manuscript. All authors have approved the final article. All authors read and approved the final manuscript.

\section{Acknowledgements}

The study was funded in part by the US National Institutes of Health ( $\mathrm{NIH}$, U54 HD070725), the Chinese Center of Disease Prevention and Control, and Xi'an Jiaotong University. The U54 project is funded by the Eunice Kennedy Shriver National Institute of Child Health and Human Development (NICHD) and the Office of the Director, National Institutes of Health (OD). Prof. Youfa Wang is the principal investigator of the study. The content of the paper is solely the responsibility of the authors and does not necessarily represent the official views of the funders. We thank study participants and school personnel who 
participated in the data collection and thank our collaborators from multiple institutions in China and the United States for their contributions to the study data collection.

\section{References}

1. Wang $Y$, Wang $L$, Qu W. New national data show alarming increase in obesity and noncommunicable chronic diseases in China. Eur J Clin Nutr. 2017;71(1):149-50.

2. Jia P, et al., Time Trend and Demographic and Geographic Disparities in Childhood Obesity Prevalence in China-Evidence from Twenty Years of Longitudinal Data. Int J Environ Res Public Health, 2017. 14(4).

3. Wang $Y$, et al. Is China facing an obesity epidemic and the consequences? The trends in obesity and chronic disease in China. Int J Obes (Lond). 2007;31(1):177-88.

4. Gao L, et al. A 3-year longitudinal study of effects of parental perception of children's ideal body image on child weight change: The Childhood Obesity Study in China mega-cities. Prev Med. 2020;132:105971.

5. Dong Y, et al. Economic development and the nutritional status of Chinese school-aged children and adolescents from 1995 to 2014: an analysis of five successive national surveys. Lancet Diabetes Endocrinol. 2019;7(4):288-99.

6. Wang Shuo DY, Wang Zhenghe Z, Zhiyong M, Jun. Trends in overweight and obesity among Chinese children of 7-18 years old during 1985-2014. Chin J Prev Med. 2017;51(4):300-5.

7. Zhao Y, et al. Fast food consumption and its associations with obesity and hypertension among children: results from the baseline data of the Childhood Obesity Study in China Mega-cities. BMC Public Health. 2017;17(1):933.

8. Zhao Y, et al. Associations between general and central obesity and hypertension among children: The Childhood Obesity Study in China Mega-Cities. Sci Rep. 2017;7(1):16895.

9. Li M, et al. Pocket money, eating behaviors, and weight status among Chinese children: The Childhood Obesity Study in China mega-cities. Prev Med. 2017;100:208-15.

10. Velde SJT, et al. Energy balance-related behaviours associated with overweight and obesity in preschool children: a systematic review of prospective studies. Obes Rev. 2012;13:56-74.

11. Ng SW, et al. The physical activity transition among adults in China: 1991-2011. Obes Rev. 2014;15:27-36.

12. Bosch $\mathrm{L}$, et al. Associations of extracurricular physical activity patterns and body composition components in a multi-ethnic population of UK children (the Size and Lung Function in Children study): a multilevel modelling analysis. BMC Public Health. 2019;19(1):573.

13. Drake KM, et al. Influence of sports, physical education, and active commuting to school on adolescent weight status. Pediatrics. 2012;130(2):e296-304.

14. Basterfield L, et al. Physical activity, sedentary behavior, and adiposity in English children. Am J Prev Med. 2012;42(5):445-51. 
15. Tanaka C, R.a.W JJ. Y.H., Longitudinal changes in objectively measured sedentary behaviour and their relationship with adiposity in children and adolescents: systematic review and evidence appraisal. Obesity reviews. 2014;15(10):791-803.

16. Cui Z, et al. Temporal trends and recent correlates in sedentary behaviours in Chinese children. Int J Behav Nutr Phys Act. 2011;8:93.

17. Tan JB, Yates S. Academic expectations as sources of stress in Asian students. Soc Psychol Educ. $2011 ; 14(3): 389-407$.

18. Vilhjalmsson R, Thorlindsson T. Factors related to physical activity: a study of adolescents. Soc Sci Med. 1998;47(5):665-75.

19. Sallis JF, et al. Parental behavior in relation to physical activity and fitness in 9-year-old children. Am J Dis Child. 1992;146(11):1383-8.

20. Fogelholm M, et al. Parent-child relationship of physical activity patterns and obesity. Int J Obes Relat Metab Disord. 1999;23(12):1262-8.

21. Li M, et al. Nutrition and physical activity related school environment/policy factors and child obesity in China: a nationally representative study of 8573 students in 110 middle schools. Pediatric Obesity. 2017;12(6):485-93.

22. Belcher BR, et al. Physical activity in US youth: effect of race/ethnicity, age, gender, and weight status. Med Sci Sports Exerc. 2010;42(12):2211-21.

23. Gortmaker SL, et al. Disparities in Youth Physical Activity in the United States: 2003-2006. Med Sci Sports Exerc. 2012;44(5):888-93.

24. Ishii K, et al. Gender and grade differences in objectively measured physical activity and sedentary behavior patterns among Japanese children and adolescents: a cross-sectional study. BMC Public Health. 2015;15:1254.

25. Gortmaker SL, et al. Disparities in youth physical activity in the United States: 2003-2006. Med Sci Sports Exerc. 2012;44(5):888-93.

26. Ji CY. and C. Working Group on Obesity in, Report on childhood obesity in China (1)-body mass index reference for screening overweight and obesity in Chinese school-age children. Biomed Environ Sci. 2005;18(6):390-400.

27. Meng L, Cheng MJ, Hou H, Zhao D, Ding X. X, Using waist circumference and waist-to-height ratio to access central obesity in children and adolescents. Chinese Journal of Evidence Based Pediatrics. 2007;3(5):324-32.

28. Biddle SJH, Bengoechea EG, Wiesner G. Sedentary behaviour and adiposity in youth: a systematic review of reviews and analysis of causality. International Journal of Behavioral Nutrition and Physical Activity, 2017. 14.

29. Mitchell JA, et al. Time spent in sedentary behavior and changes in childhood BMI: a longitudinal study from ages 9 to 15 years. Int J Obes (Lond). 2013;37(1):54-60. 
30. Li M, et al. Parental Expectations and Child Screen and Academic Sedentary Behaviors in China. Am J Prev Med. 2017;52(5):680-9.

31. lannotti RJ, Wang J. Trends in Physical Activity, Sedentary Behavior, Diet, and BMI Among US Adolescents, 2001-2009. Pediatrics. 2013;132(4):606-14.

32. De Baere S, et al., Temporal patterns of physical activity and sedentary behavior in 10-14 year-old children on weekdays. Bmc Public Health, 2015. 15.

33. Yi XQ, et al. Prevalence and risk factors of obesity among school-aged children in Xi'an, China. Eur J Pediatr. 2012;171(2):389-94.

34. Zhang T, et al., The prevalence of obesity and influence of early life and behavioral factors on obesity in Chinese children in Guangzhou. Bmc Public Health, 2016. 16.

35. Watanabe E, et al., Clustering patterns of obesity-related multiple lifestyle behaviours and their associations with overweight and family environments: a cross-sectional study in Japanese preschool children. Bmj Open, 2016. 6(11).

36. Sun YC, Sekine M, Kagamimori S. Lifestyle and Overweight Among Japanese Adolescents: The Toyama Birth Cohort Study. Journal of Epidemiology. 2009;19(6):303-10.

37. Biddle SJ, Garcia Bengoechea E, Wiesner G. Sedentary behaviour and adiposity in youth: a systematic review of reviews and analysis of causality. Int J Behav Nutr Phys Act. 2017;14(1):43.

38. Zhu Z, et al. Physical activity, screen viewing time, and overweight/obesity among Chinese children and adolescents: an update from the 2017 physical activity and fitness in China-the youth study. BMC Public Health. 2019;19(1):197.

39. Ren $\mathrm{H}$, et al. Excessive homework, inadequate sleep, physical inactivity and screen viewing time are major contributors to high paediatric obesity. Acta Paediatr. 2017;106(1):120-7.

40. Health C. o.S.M.a.F.C.o.S., Active Healthy Living: Prevention of Childhood Obesity Through Increased Physical Activity. Pediatrics. 2006;117(5):1834-42.

41. Gorobets A. Development of bicycle infrastructure for health and sustainability. Lancet. 2016;388(10051):1278.

42. Larouche R, et al. Associations between active school transport and physical activity, body composition, and cardiovascular fitness: a systematic review of 68 studies. J Phys Act Health. 2014;11(1):206-27.

43. Mendoza JA, et al. Active commuting to school and association with physical activity and adiposity among US youth. J Phys Act Health. 2011;8(4):488-95.

44. Larouche R, et al. Relationship between active school transport and body mass index in grades 4-to- 6 children. Pediatr Exerc Sci. 2011;23(3):322-30.

45. Engberg E, et al. Heavy screen users are the heaviest among 10,000 children. Sci Rep. 2019;9(1):11158.

46. Maher $\mathrm{C}$, et al. Screen time is more strongly associated than physical activity with overweight and obesity in 9- to 16-year-old Australians. Acta Paediatr. 2012;101(11):1170-4. 
47. Harrison F, Jones AP. A framework for understanding school based physical environmental influences on childhood obesity. Health Place. 2012;18(3):639-48.

48. Williams AJ, et al. A systematic review of associations between the primary school built environment and childhood overweight and obesity. Health Place. 2012;18(3):504-14.

49. Jia P, et al. School environment and policies, child eating behavior and overweight/obesity in urban China: the childhood obesity study in China megacities. Int J Obes (Lond). 2017;41(8):1310.

50. Rashad Kelly l, et al. Contribution of the school environment to physical fitness in children and youth. J Phys Act Health. 2010;7(3):333-42.

51. Zhu W, et al. Physical education and school contextual factors relating to students' achievement and cross-grade differences in aerobic fitness and obesity. Res Q Exerc Sport. 2010;81(3 Suppl):S53-64.

52. Fernandes M, Sturm R. Facility provision in elementary schools: correlates with physical education, recess, and obesity. Prev Med. 2010;50(Suppl 1):S30-5.

53. Zhang $P$, et al. The Association between Family and Parental Factors and Obesity among Children in Nanchang, China. Front Public Health. 2016;4:162.

54. Bates CR, Nicholson BJ, Cory LM, Jagpal M A and Bohnert AM. Links between the organization of the family home environment and child obesity: a systematic review. obesity reviews. 2017;19(5):71627.

\section{Figures}
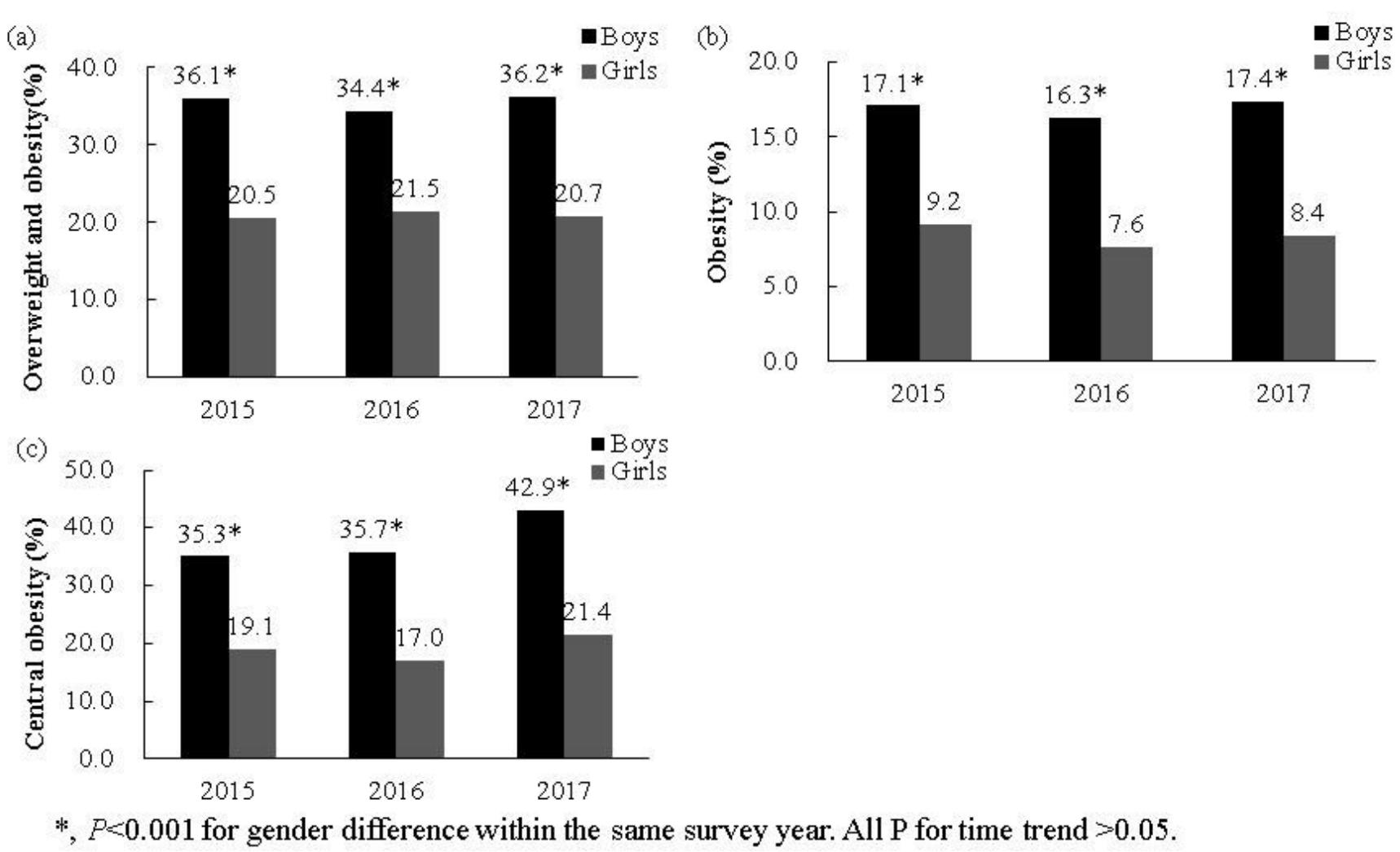

Figure 1 
Prevalence of overweight and obesity (a), obesity (b) and central obesity (c) among school children in 5mega cities in China 2015-2017. *, P 0.001 for gender difference within the same survey year. All $P$ for time trend $>0.05$.
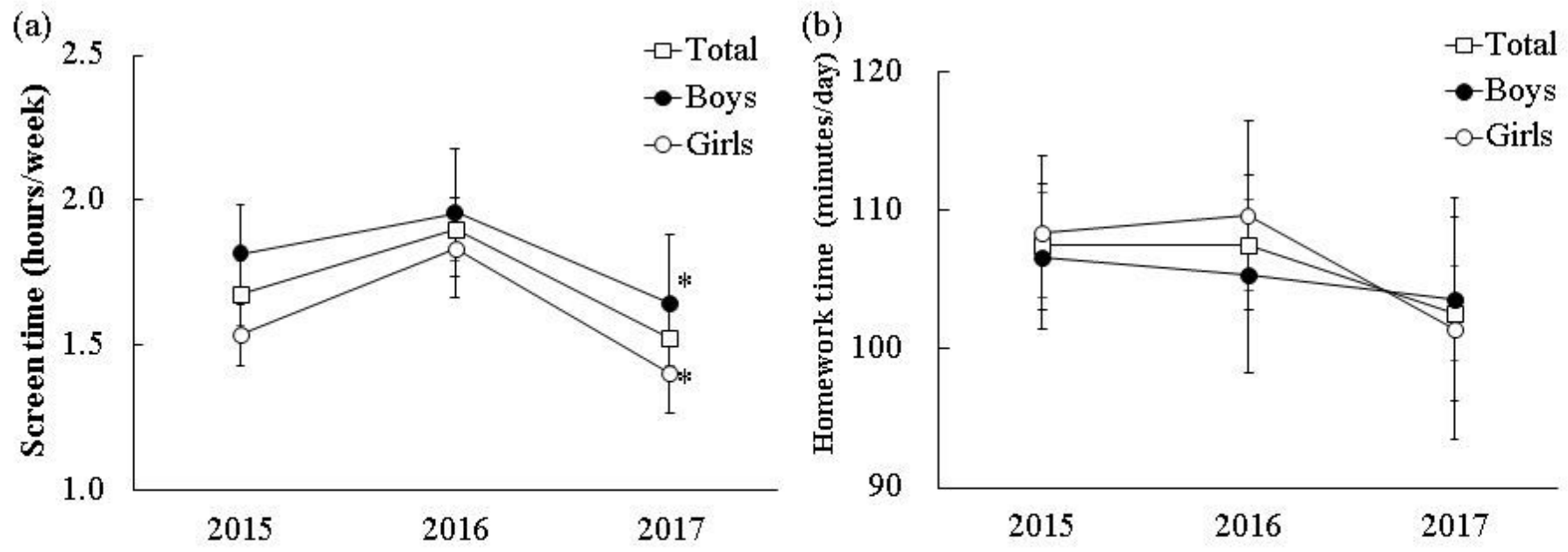

Data were presented as mean $(95 \% \mathrm{CI})$. " , Students who participated in the survey for the first time during 2015 2017 were included. ${ }^{*}, \mathrm{P}<0.05$ between 2015 and 2017 . All $\mathrm{P}$ for time trend $>0.05$.

No gender difference in any survey year was observed.

\section{Figure 2}

Trends in screen time (a) and homework time (b) of school children in 5-mega cities in China 2015-2017\# Data were presented as mean $(95 \% \mathrm{Cl})$. \#, Students who participated in the survey for the first time during 2015-2017 were included. * $P<0.05$ between 2015 and 2017. All $P$ for time trend $>0.05$. No gender difference in any survey year was observed. 